\title{
Price discovery on traded inflation expectations: does the financial crisis matter?
}

\author{
Alexander Schulz and Jelena Stapf ${ }^{1}$
}

\section{Introduction}

For a central bank to fulfil its price stability mandate, the accurate assessment of inflation expectations is of crucial importance. Market participants gauging long-term investments have similar concerns about inflation. Traditionally, inflation expectations have been derived from models or through surveys of market participants' opinions. In the mid to late 1990s financial markets started to trade claims on inflation actively. Analyzing this source of information has become standard by now. However, there are two main categories in which inflation claims are traded: inflation-linked bonds and inflation swaps. Which market can process information about inflation more quickly and with more impact on long-run equilibrium prices? Is it the size of the respective market that drives the lead in processing inflation information via BEIR? Has the financial crisis changed the price discovery process and biased it more towards one instrument? These are the key questions posed by this paper.

A huge body of literature exists on how to extract inflation expectations from financial market data. However, as far as we know, price discovery for BEIR has not previously been analysed on an intraday basis. This paper fills the gap.

Information shares of BEIR are large for central government bonds especially with longer maturities. The larger size of the inflation-indexed bond market in the United States compared to the euro area bias the price discovery process even more towards the bond market. Whereas, in times of financial crisis, heightened risk aversion generally obstructs trades on financial markets, contributions to price formation have concentrated more on government bonds, presumably the safest financial instrument.

We make use of the approximate arbitrage relationship that exists between bond BEIR and swap BEIR. Graph 1 shows that these instruments do indeed react on news concerning actual and future inflation rates and serves as a first illustration of the close relationship between them. Whereas in practice inflation swaps and nominal and real government bonds are different instruments and therefore differ in prices, the inflation information embedded in these instruments is the same. By means of arbitrage this restricts large price deviations between both instruments. The classical price discovery measures as developed by Hasbrouck (1995) and Gonzalo and Granger (1995) have been applied to the same instrument, eg a share trading in different local markets. We follow the approach used by Blanco, Brennan and Marsh (2005) and explore price discovery of the same cash flows, in our case BEIR, traded with different instruments on different markets.

1 Authors: Alexander Schulz, Deutsche Bundesbank, email: alexander.schulz@bundesbank.de and Jelena Stapf, Deutsche Bundesbank, email: jelena.stapf@bundesbank.de. We thank Christoph Fischer, Joachim Grammig, Joseph Haubrich, Thomas Laubach, Franziska Peter, Stefan Reitz as well as seminar participants at the Annual Congress of the EEA in Barcelona 2009, the International Conference on Macroeconomic Analysis and International Finance in Crete 2009 and Deutsche Bundesbank for helpful comments. All remaining errors are ours. The opinions expressed in this paper do not necessarily reflect the opinions of the Deutsche Bundesbank or its staff. 


\section{Graph 1}

Yield of inflation-indexed bond with maturity 2012 and four-year inflation swap rate on 5 June 2008

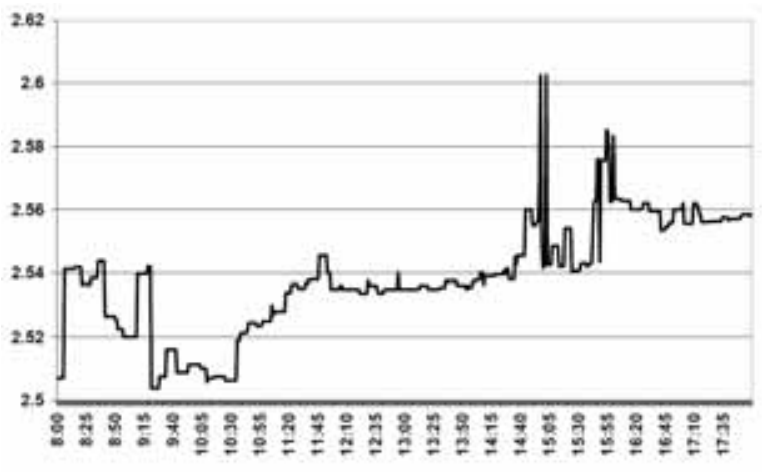

(a) Bond BEIR

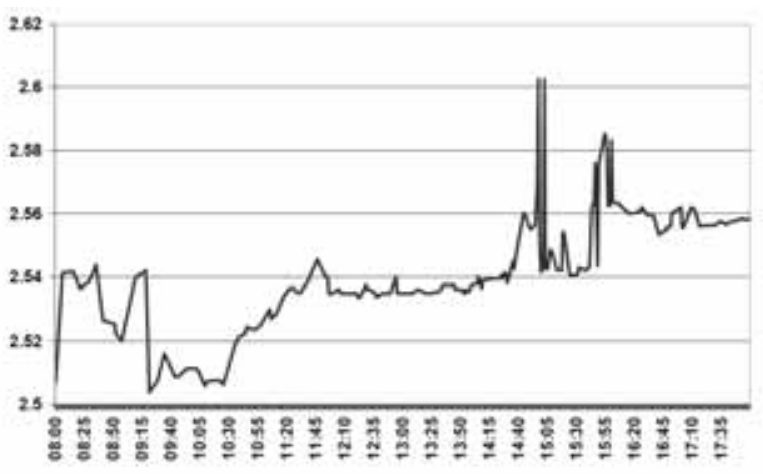

(b) Swap BEIR

President Trichet's remarks in the ECB press conference starting at $2.30 \mathrm{pm}$ were widely regarded as the turn in the euro interest rate cycle.

We measure the contribution of each market's price innovation to a common efficient price. We use a high-frequency dataset of the respective bonds and swaps at one-minute intervals. Our sample periods range from May to December 2008. The considered period contains both rising and declining inflation expectations, a turning point of monetary policy and the spread of a severe financial crisis.

The euro area index-linked bond market is rather partitioned, with different credit ratings of issuers and two relevant inflation indices. Thus liquidity is dispersed. Against this backdrop, the euro inflation swap market developed very well recently ((Hurd and Relleen (2006), Deacon, Derry, and Mirfendereski (2004)). On the other side of the Atlantic, the United States maintains a well established issuance programme for Treasury Inflation Protected Securities (TIPS) and exhibits only a small inflation swap market. Therefore, we expect the swap market to lead price discovery in the euro area and the bond market in the United States. However, these priors do not stand fully up to empirical evidence. In the euro area for shorter maturities up to five years, new information comes from both markets, whereas for horizons of seven years and above the bond market increasingly leads the price discovery process. In the United States, the bond market dominates the price discovery process for all maturities. Only for the shortest time horizon, one third of price innovations comes from the swap market. Especially with longer maturities central government bonds are the benchmark for hedging inflation risk and for pricing inflation expectations in both currency areas.

The severe financial crisis that broke out in autumn 2008 drove a wedge between bond BEIR and swap BEIR in both currencies. Price discovery ceased to take place on the swap market. Disruptions coming from the short end of the market even separated price formation in both segments for maturities of up to six years in the United States. Thus even though the swap curve exhibits at times a smoother pattern than its bond derived equivalent it is not adequate to exclude bonds from the inflation expectations analysis.

The remainder of the paper is organised as follows: the next section introduces the respective markets where inflation expectations trade. It also shows how arbitrage guarantees price proximity. Section 3 contains a description of our dataset. In Section 4 we explain the econometric method used and Section 5 shows the results of our analysis of price discovery for euro area and US data. The last section concludes. 


\section{Two markets for trading inflation expectations}

Inflation has become a standard commodity on financial markets or, to put it differently, a well accepted index to which financial claims can be linked. In the following we briefly describe the two most relevant markets for inflation-indexed claims: bonds and swaps.

\subsection{The inflation-indexed bond market}

The United Kingdom pioneered the use of inflation-protected bonds. Inflation-linked gilts (giltedged securities) were first sold in $1981 .{ }^{2}$ But only the start of the US TIPS programme in 1997 led the way for several other countries. Today, the US market is the largest for inflationprotected bonds. The amount outstanding is $\$ 516$ billion, which is more than $9 \%$ of overall Treasury notes, bonds and bills issuance. ${ }^{3}$ TIPS are linked to the US city average all-items consumer price index for all urban consumers (CPI-U). Within the euro area, France, Greece, Italy and Germany have indexed bonds outstanding. France is by far the most active issuer here, sponsoring two programmes linked to the national CPI (ex-tobacco, first issue in 1998 ) and the euro area harmonised index of consumer prices (HICP, again ex-tobacco HICPXT, first issue in 2001), respectively. The combined amount outstanding is $€ 137$ billion. Germany issued linkers in 2006 and has built up a volume outstanding of $€ 22$ billion. While German and French bonds enjoy a AAA rating, Italian government paper (€81 billion outstanding, start in 2003) and Greek government bonds (€15 billion outstanding, 2003) are lower-rated. They trade at a spread to German and French bonds.

We infer inflation compensation by subtracting real yields derived from inflation-linked bonds from nominal bond yields using the Fisher equation. ${ }^{4}$ Yet bond yields not only incorporate inflation and real yields or growth expectations. Investors require in addition compensation for unexpected future inflation rate changes in nominal bonds and for illiquidity, default risk and other risk in nominal and inflation-protected bonds. Hence, the BEIR comprises everything that is not uniformly priced or not compensated on both nominal and inflationlinked bond markets (see Figure 1). To begin with, the BEIR contains inflation expectations among financial market participants. Secondly, an inflation risk premium reflects the compensation that nominal bond holders require for unexpected inflation rate changes whereas the inflation-indexed bond holder is not exposed to that risk. Liquidity might be different on the two markets. Nominal bond markets are larger in volume and might therefore be more liquid. To get exposure to a BEIR one can either go long a nominal bond and short an inflation-linked bond or vice versa. The cost of carry for both bonds is different and therefore has implications for the level of the BEIR. Repo specialness, delivery options for futures and other institutional features might drive bond yields on both markets further apart. ${ }^{5}$ Since we use pairwise government bonds from the same issuer, default risk is not an issue here.

2 See Campbell and Shiller (1996) for an overview of early linkers, including issues from emerging markets.

3 As of January 2009. Relative to its outstanding marketable debt the UK is still the largest issuer, with a share of $28 \%$.

4 See Section 4 for a more formal representation.

5 A repo or repurchase transaction is a standard technique for funding purchases of financial instruments, which are themselves used as collateral. See Buraschi and Menini (2002) for a discussion of specialness. 
Figure 1

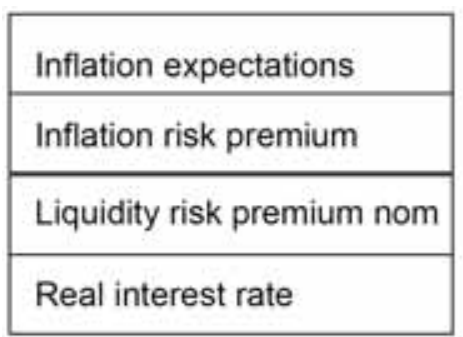

Nominal bond

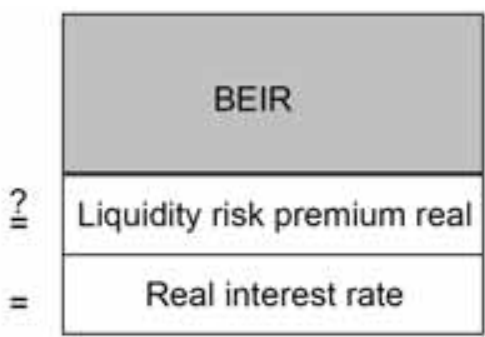

Real bond

The BEIR derived from nominal and real bonds contains inflation expectations as well as the inflation risk premium and the difference of the respective bonds' liquidity premia.

\subsection{The inflation swap market}

Markets for inflation-linked derivatives have grown quickly in recent years. Their development has been complementary to those of inflation-indexed bonds. The most important segment of the inflation derivatives market are inflation swaps. These are traded in the over-the-counter market (OTC) by financial institutions, fund managers and corporate treasurers. The inflation swap is a bilateral contract which requires one party to the contract (the inflation receiver) to make predetermined fixed-rate payments in exchange for floating-rate payments linked to inflation from a second party (the inflation payer). The basic building block of inflation swap structures is the zero coupon inflation swap, where payments are exchanged only on maturity. Typical maturities range from one year to more than 30 years.

Euro zero coupon swaps are in general linked to the same index as most bonds in the associated market. They pay the initially published non-seasonally adjusted euro zone HICPXT; possible later revisions have no effect. The inflation index is subject to a lag of three months. This ensures that both swap parties know the reference price level at the start of the contract. Unlike inflation-linked bonds the reference price level for each day is not interpolated between two adjacent months but changes at the end of the month. This involves jumps at the day of the change of the month especially for shorter maturities but has the advantage that a swap can be traded and unwound in the same month without incurring future inflation risk (an interpolated swap would retain some inflation risk). US zero coupon swaps are linked to the non-seasonally adjusted CPI-U and have an interpolated reference price level for each day as base as well as an indexation lag of three months. This closely aligns the swap market with the US bond market.

Although a modest amount of inflation-linked trades has taken place in continental Europe since the early 1990s, euro inflation swap volumes did not start to boom before the early 2000s. The issuance of bonds linked to the euro zone HICPXT from the French and Italian government in 2001 and 2003 respectively supported the proliferation of the euro swap market. In 2007 the monthly notional amount traded was estimated at a two-digit number of billion euros. Euro inflation swaps were regarded as one of the fastest-growing OTC derivative contracts. In contrast to the euro area, the inflation swap market in the United States developed while the inflation-linked bond market had already been in existence for some years. In 2004, when TIPS issuance picked up, USCPI swaps also became more popular. Yet an estimated trading volume of $\$ 11$ billion in 2007 is small compared to that of the inflation-indexed bond market (Peat and Segregeti (2008)).

Inflation swaps explicitly target changes in the price level. Thus the swap BEIR is simply the quoted fixed rate agents are willing to pay in order to receive the cumulative rate of realised 
inflation during the life of a zero coupon swap. The swap BEIR depends on expected inflation over the life of the swap as well as on various risk premia. Again, these premia comprise compensation for unexpected inflation rate changes and liquidity. ${ }^{6}$

Compared to bonds, inflation swaps are a new instrument, which suggests an illiquid market. However, market reports indicate that the trading volume of swaps clearly exceeds those of indexed bonds, which is of course partly due to the fact that entering a swap does not involve funding costs. That notwithstanding, market intelligence suggests that there is a lack of inflation payers, which results in inflation paid via swaps having a higher price than via bonds (Armann, Benaben and Lambert (2005) and ECB (2006b)).

The swap BEIR may involve in addition a premium for counterparty risk. Payments are typically exchanged between two private corporations, mostly banks and broker firms but also hedge funds, insurers and non-financial corporations. Therefore the degree of creditworthiness attached to these payments is typically lower than that of bonds issued by governments. Since the market trades mostly zero coupon swaps with payments only exchanged on maturity, the counterparty risk especially for long-term swaps could be prohibitively high. Collateralisation tackles that problem and has become increasingly popular among OTC derivatives users during the last years. The International Swaps and Derivatives Association (ISDA) states that $66 \%$ of fixed income OTC derivatives were collateralised in 2008 compared with 48\% in 2003 (ISDA (2005 and 2008)). However, a special kind of counterparty risk remains even for fully collateralised swaps: the default-to-replacement risk. This risk came to the attention of a broader audience with the collapse of the investment bank Lehman Brothers in September 2008 and contains two related risks. Firstly, collateral is valued at the margin. This means that in case of default the creditor who seeks a replacement has only a marginal price impact. Yet when Lehman collapsed a huge number of swaps needed to be replaced at the same time. This obviously had more than a marginal impact. A shift in risk aversion might put additional stress on prices. Furthermore, especially in a one-sided market it will take some time to close open positions. This exposes the creditor to general market risk (eg a monetary policy shock that could move inflation expectations) on top of the direct effect of the default. Again, this risk occurring after the default is not covered by collateral.

\subsection{Pricing and arbitrage}

There exists a huge body of literature on how to extract inflation expectations from financial market data. The literature is largely driven by staff members of investment banks and central banks. Whereas the former are more concerned with pricing and valuation of inflation-indexed bonds and derivatives for trading reasons (Peat and Segregeti (2008) and Kerkhof (2005)) the latter focus more on pure long-term inflation expectations as an indicator of the credibility of their monetary policy (ECB (2006a), Hurd and Relleen (2006), Wright (2008) and Kim and Wright (2005)). Over the last 15 years especially the search for measures of inflation risk premia, liquidity and other risks that cloud inflation expectations has proliferated. However, the price discovery process on traded inflation expectations has been ignored so far.

Following Blanco, Brennan, and Marsh (2005) and Doetz (2007), we assume that if different instruments spanning the same economic concept or payments, eg credit risk in their case and BEIR in our case, arbitrage will tie the prices of these instruments together. Otherwise the same claim, credit protection in their case and inflation protection in our case, could be bought more cheaply on one market than on the other. Given that we compare the prices of

6 Liu, Longstaff and Mandell (2006) deal comprehensively with liquidity and default risk in interest rate swaps; as far as we know, no similar study exists for inflation swaps. 
related but not identical instruments, we conform with the literature in speaking of an approximate arbitrage relationship. Yet we also take into account the finding that derivative markets have shifted trading away from spot markets - mostly due to lower funding costs and are increasingly recognised as taking the lead in price formation, especially in financial crisis conditions (Upper and Werner (2007)).

Figure 2
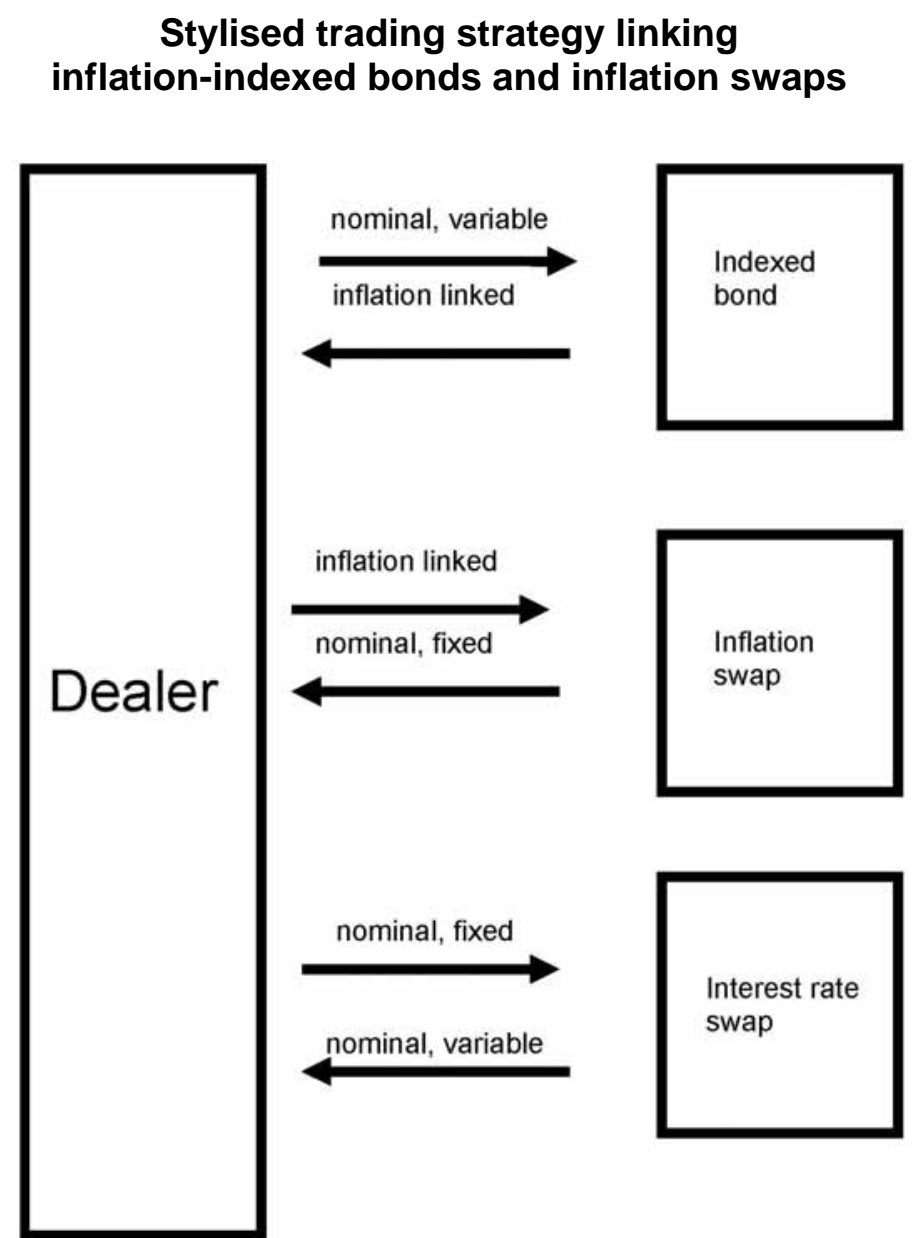

Dealer buys inflation-indexed bonds, funds the purchase with a repo and sells inflation protection into the swap market. The nominal swap closes the position.

In practice, an asset swap is the instrument that links bond and swap prices. An asset swap exchanges a fixed investment, such as a bond with coupon payments, for a floating investment, such as Euribor plus a spread. While nominal asset swaps have been established for some time, real or inflation-linked asset swaps have become popular only during the last five years. As in a standard asset swap, the proceeds of a bond are exchanged against a floating rate interest payment, except that the proceeds are not fixed but inflation-linked. Thus, a dealer might buy an indexed bond via a repo, provide an inflation-indexed cash flow to the market via an inflation swap and hedge its position with a standard interest rate swap (Figure 2). ${ }^{7}$ The fact is that the financing constraints of dealers,

7 See Armann, Benaben and Lambert (2005) p 94, and Deacon, Derry, and Mirfendereski (2004), Chapter 9, for a lucid treatment. 
maturity mismatches stemming from the low number of available indexed bonds and other transaction costs will hamper arbitrage. Differences in market liquidity both within the bond market and between bond and swap market as well as variations in credit exposure impede price equality. Regulatory barriers preventing investors to engage in derivative instruments or shorten bonds further affect the balance of prices. Thus a constant spread between the two break-even rates can and does prevail. However, markets prove to be sufficiently liquid to keep up the arbitrage relationship between bond and swap BEIR in most cases.

\section{Data}

Our dataset consists of real and nominal bonds, as well as inflation swaps. To avoid a credit bias, we concentrate on French and German bonds that all have a AAA rating in the euro area. Furthermore, we focus on the HICPXT as a reference for both inflation swaps and bonds; hence we remove bonds linked to the French national CPI from our sample. ${ }^{8}$ The US sample contains TIPS with residual maturities from two to 10 years as well as Treasury Notes and inflation swaps with equal maturities. We use two sample periods ranging from May/June to August and from September to December 2008 which we label Summer and Autumn 2008 respectively.

All bonds are capital-indexed, ie their notional is inflated with the change of the price index. Coupon and redemption payments are made on the adjusted notional. There is some protection against severe and persistent deflation, as redemption is never below the initial notional. In addition, we restrict the euro area sample to bonds with maturities of up to 12 years, as these are tenors for which inflation swaps are actively traded. ${ }^{9}$ Altogether, we keep six linkers in our sample covering maturities of two, four, five, seven, eight and 12 years. We select six adequate nominal bonds to compute the BEIR (see Table A-1 in the Appendix for a list of bonds used). The United States operates the world's most active issuing programme; thus we are able to investigate the term structure of bond BEIRs from two to 10 years for whole-year tenors (see Tables A-2 and A-3 in the Appendix). ${ }^{10}$ Inflation swaps with corresponding tenors form the alternative market.

We obtained bid and ask prices for bonds as well as for swaps, all on one-minute intervals. Furthermore we received the number of quote changes (ticks) in each minute. This gives us an indication of the market's liquidity. As we do not have transaction data, we use the midpoint of bid and ask quotes as the hypothetical transaction price. ${ }^{11}$ For the euro area, we use quotes between 8 am and 6 pm as hardly any trading takes place in the interim time. The Summer and Autumn datasets range from 5 May to 8 August 2008 and from 2 September to 8 December 2008 respectively. Each set spans 70 trading days. Given the adjustments described above, 439,000 swap midpoints remain in our sample as well as about 315,000 observations of nominal bond prices and 185,000 of indexed bonds (see Table A-4 in the Appendix). Claims on US inflation are traded between 9 am and midnight European Central Time. We obtained data for the Summer sample from 12 June 2008 to 13 August 2008 and for the Autumn period from 3 September 2008 to 9 December 2008. This makes a total of approximately 520,000 quotes for the nine nominal bonds, 324,000 for

France as a pioneer issuer of inflation-linked debt in the euro area has set the standard for linking claims on an index excluding tobacco products, thus providing a control for manipulated prices to some degree.

9 As reported on Bloomberg. For longer horizons, eg the French bond expiring in 2040, we would need to interpolate between infrequently traded 30- and 40-year inflation swap rates, which is prone to errors.

10 All bonds except for the five-year tenors are off-the-run.

11 Intervals with only either a bid or an ask entry are eliminated. 
the inflation-indexed bonds and 858,000 quotes for the matching inflation swaps (see Table A-5 in the Appendix). Prices are carried forward until a new quote is available. All data is taken from Bloomberg.

Bond prices are transformed into yields. We use the yield-to-maturity or redemption yield concept to calculate bond yields from our price data. The bond yields are therefore systematically slightly undervalued compared to the zero coupon yields from our inflation swap data. ${ }^{12}$ The prices for the bond data reflect a decreasing time to maturity whereas the inflation swaps are quoted daily in whole year tenors. To establish comparability we adjust the yields of the bond to whole year tenors as well. We use daily estimates of term structures of nominal and real bonds to increase (decrease) the yields of our bonds from the remaining time to maturity to whole year tenors.

Furthermore, we need to correct real bond yields for seasonality effects. These occur because bonds are linked to non-seasonally adjusted inflation indices and yields can be biased especially for shorter maturities. ${ }^{13}$ For example, in the euro area consumer prices are typically low in January (high in April). January (April) is indeed the reference month for inflation compensation of German (French) bonds. Investors buying bonds at any other time during the year adjust the price according to the higher (lower) actual non-seasonally adjusted inflation rates and therefore under- (over)estimate the bond yield and the BEIR respectively. We correct for seasonality via daily seasonal factors extrapolated from monthly seasonally adjusted and non-seasonally adjusted CPI data. ${ }^{14}$ The same adjustments are performed on US data. Yet due to the semiannual coupon payments of US bonds the issue of seasonality is less virulent.

The respective competitive market comprises six inflation swaps for the euro area and nine for the US with tenors equivalent to the bond BEIR. Since we consider only swaps with fullyear tenors we need to correct for neither maturity nor seasonality.

\section{Price discovery: Measurement method}

If both the swap and the bond market price inflation expectation plus risk premia equally, bond BEIR and swap BEIR of the same maturity should be identical. Subject to the arbitrage imperfections noted above the difference between the two measures - here called the basis - should be non-zero. Nevertheless a positive (negative) mean of the basis would imply that there are irrevocable costs attached to the investment that makes the hedging of inflation exposure more costly (more attractive) in one market.

The basis for a given tenor, $t$, is defined as:

basis $_{t}=$ swapBEIR - bondBEIR $R_{t}$

where:

bondBEIRt $=\left[\left(\frac{1+y_{t}^{n}}{1+y_{t}^{r}}-1\right) * 100\right]$.

and $y_{t}^{n}$ and $y_{t}^{r}$ are the yields of the nominal respectively real bond.

12 Calculating true zero coupon yields for our high-frequency bond price data is nearly impossible, as necessary interpolations are prone to contaminate the marginal price change of a single bond.

13 Only on coupon dates is there no bias as inflation is paid out. For an explanation and visualisation of seasonality in CPI, see, for example, Peat and Segregeti (2008) p 183.

14 See Eijsing, Garcia, and Werner (2007) for further explanations of the adjustment method. 
In the BEIR, implicit inflation expectations are traded in the swap and the bond market. Price discovery is the process by which prices embed new information in either one or both of the two markets. Arbitrage implies that prices cannot deviate too far. In econometric terms, prices are cointegrated I(1) variables which means that the price series have one or more common stochastic factors. If we assume that there is one cointegration relation only and therefore one common factor, we can thus term this factor the implicit efficient price. It is this price driven by new information which is the source of the permanent movement in the prices of both markets. The price discovery can be analysed with two alternative concepts: Hasbrouck's information shares (Hasbrouck (1995)) and Gonzalo and Granger's contributions to the common factor (Gonzalo and Granger (1995)). ${ }^{15}$ Hasbrouck defines price discovery in terms of the variance of all innovations in a vector error correction model (VECM) to the common factor. Gonzalo Granger involves only permanent shocks where each market's contribution to the common factor is defined to be a function of only the error correction coefficient in a VECM. Hasbrouck information shares use contemporaneous correlations between price innovations in both markets as much as the variance of these innovations whereas Gonzalo Granger does not. In the following we compute both measures.

If the two prices are I(1), cointegrated and have the $r^{\text {th }}$ order vector autoregression representation:

$p_{t}=\Theta_{1} p_{t-1}+\cdots+\Theta_{r} p_{t-r}+\varepsilon_{t}$,

where $p_{t}=\left(p_{1, t}, p_{2, t}\right)^{\prime}$. It follows that the returns:

$\Delta p_{t}=\left[\begin{array}{l}p_{1, t}-p_{1, t-1} \\ p_{2, t}-p_{2, t-1}\end{array}\right]$,

evolve according to the Engle and Granger (1987) representation theorem in a bivariate equilibrium correction process

$\Delta p_{t}=\alpha z_{t-1}+A_{1} \Delta p_{t-1}+\cdots+A_{r} \Delta p_{t-r-1}+\varepsilon_{t}$,

where $z_{t-1}$ is the error correction term and $\varepsilon_{t}$ is a zero-mean vector of serially uncorrelated innovations. $z_{t}$ is a vector of differences in prices between markets and because swap BEIR are not directly comparable to bond BEIR includes coefficient $\beta_{2}$, that adjusts for daily changes in the basis and a constant $c$ :

$$
\begin{gathered}
z_{t-1}=\left[p_{1, t-1}-\beta_{2} p_{2, t-1}-c\right], \\
z_{t-1}=\beta^{\prime} p_{t-1} .
\end{gathered}
$$

Following the Stock and Watson (1988) permanent-transitory decomposition, Hasbrouck (1995) transforms equation (3) into a vector moving average (VMA) representation and its integrated form:

$$
p_{t}=\Psi(1) \sum_{s=1}^{t} \varepsilon_{s}+\Psi^{*}(L) \varepsilon_{t},
$$

where $\Psi^{*}(L)$ is a matrixpolynomial in the lag operator, $L . \Psi(1)$ represents the permanent effect of the shockvector on all the cointegrated security prices, with $\Psi(1) \varepsilon_{t}$ being the long-

15 See Hasbrouck (1995), Baillie, Bootha, Tse and Zabotinac (2002), Mizrach and Neely (2005) or Grammig and Peter (2008) for derivations and a discussion of both measures. 
run impact of an innovation in t. Under the assumption of a single common factor, the longrun multipliers $\Psi(1)$ can be provided in the error correction framework as Baillie, Bootha, Tse and Zabotinac (2002) show:

$\Psi(1)=\beta_{\perp} \pi \alpha_{\perp}^{\prime}$,

$\Psi(1)=\pi\left[\begin{array}{ll}\gamma_{1} & \gamma_{2} \\ \gamma_{1} & \gamma_{2}\end{array}\right]$.

Since we assumed a single common factor $\pi$ is a scalar and $\beta_{\perp}$ and $\alpha_{\perp}$ are the orthogonal complements of the original parameter vectors in (5) and (6).

Because the prices are cointegrated, each error term must have the same long-run impact on prices. This means that all the rows in (8) are identical. If the covariance matrix $\Omega$ of the residuals $\varepsilon_{t}$ is diagonal, ie the contemporaneous correlation of the residuals is zero, the information share of market 1 is defined by:

$S_{1}=\frac{\gamma_{1}^{2} \sigma_{1}^{2}}{\gamma_{1}^{2} \sigma_{1}^{2}+\gamma_{2}^{2} \sigma_{2}^{2}}$.

If there is correlation between the error terms, ie $\rho \neq 0$, Hasbrouck (1995) suggests a Choleski factorisation of the covariance matrix such that $\Omega=M M^{\prime}$, where $M$ is a lower triangular matrix. ${ }^{16}$ The Hasbrouck information shares for market 1 and 2 are then defined as:

$$
\begin{aligned}
& H_{1}=\frac{\left(\gamma_{1} m_{11}+\gamma_{2} m_{12}\right)^{2}}{\left(\gamma_{1} m_{11}+\gamma_{2} m_{12}\right)^{2}+\left(\gamma_{2} m_{22}\right)^{2}}, \\
& H_{2}=\frac{\left(\gamma_{2} m_{22}\right)^{2}}{\left(\gamma_{1} m_{11}+\gamma_{2} m_{12}\right)^{2}+\left(\gamma_{2} m_{22}\right)^{2}} .
\end{aligned}
$$

That is market 1 information share is the proportion of the variance in the common factor that is attributable to shocks in market 1 . The factorisation imposes a greater information share on the first price (unless $m_{12}=0$ ). Therefore upper (lower) bounds of information shares are calculated when market 1 is first (second) in the ordering of the variables for the factorisation. In the following we calculate midpoints of the upper and lower bounds of the Hasbrouck shares induced by the different orderings of the variables.

An alternative measure for price discovery is based on the Gonzalo and Granger (1995) decomposition of the price vector into a permanent, $g_{t}$, and a transitory, $f_{t}$, component:

$p_{\ell}=\theta_{1} g_{t}+\theta_{2} f_{t}$,

where the permanent component is a linear combination of the prices in the two different markets, $g_{t}=\Gamma p_{t}$, ie $\Gamma$ is the common factor coefficient vector. The additional identifying restriction that $f_{t}$ does not Granger-cause $g_{t}$ implies that $\theta_{1}=\beta_{\perp} \alpha_{\perp}^{\prime}=\left(\gamma_{1}, \gamma_{2}\right)^{\prime}$. The weights given to price discovery are then defined as:

$$
G G_{1}=\frac{\gamma_{1}}{\gamma_{1}+\gamma_{2}} \text {. }
$$

16 The covariance matrix is $\Omega=\left[\begin{array}{cc}\sigma_{1}^{2} & \rho \sigma_{1} \sigma_{2} \\ \rho \sigma_{1} \sigma_{2} & \sigma_{2}^{2}\end{array}\right]$ and the lower triangular matrix is
$M=\left[\begin{array}{cc}m_{11} & 0 \\ m_{12} & m_{22}\end{array}\right]=\left[\begin{array}{cc}\sigma_{1} & 0 \\ \rho \sigma_{2} & \sigma_{2}\left(1-\rho^{2}\right)^{1 / 2}\end{array}\right]$ 


\section{Price discovery in the euro area and the United States}

We first address the problem implied by the short time horizon of our dataset. In the remainder of this section, we lay out price discovery, first in the comparatively calm period of the Summer and subsequently in the crisis phase of Autumn 2008. Price discovery with forward rates is presented in the last subsection.

Since our datasets each span only 70 trading days - and only 45 for the United States - the use of cointegration techniques that target long-run equilibria might appear inappropriate. Yet we are investigating an (near) arbitrage relationship on a financial market, where corrections to deviations from equilibrium could be effected instantaneously or, in our case, every minute. Therefore we expect the half-life of deviations to be short-lived. Indeed, the average half-life of a deviation across all maturities and both markets is around $3 \frac{1}{2}$ hours in the euro area and $7 \frac{1}{2}$ hours in the United States in Summer 2008. If we set the length of our dataset in relation to this average half-life, as is proposed by Hakkio and Rush (1991), we get a ratio of 190 or 94 respectively. Studies testing for purchasing power parity where cointegration is routinely applied featuring half-lives of three to five years (Rogoff (1996)). They would need more than 300 years of data to match a ratio of 100 . However, the half-life of deviations increases to more than 40 hours for euro area data and over 120 hours in the United States in our extreme crisis sample in Autumn 2008. This implies a ratio of the length of the dataset to the average half-life of 16 or 6 respectively and gives a first hint that trades and the adjustment to a common efficient price were distinctly slower during the financial crisis period.

\subsection{Summer 2008: The baseline scenario}

Data for the difference between swaps and bonds, ie the basis, show that this is significantly positive (see Graph 2 and Table 1). For all maturities - except the shortest in the United States - the basis is meaningfully greater than zero, implying that the BEIR derived from swaps lies uniformly over the bond BEIR. One part of this difference stems from our use of yields to maturity for bonds versus zero coupon yields for swaps. If the yield curve does not run completely flat, as is the case in our sample, yields to maturity are lower than zero coupon yields. The difference can be up to 8 basis points as shown by a zero coupon dataset with daily frequency for both BEIR. Nevertheless a significant and positive basis persists although it is on average smaller than that of our high-frequency dataset. This is in line with previous literature assessing the higher swap yield to liquidity considerations and other risk premia (Armann, Benaben and Lambert (2005), Campbell, Shiller and Viceira (2009) and Deacon, Derry and Mirfendereski (2004)).

\section{Graph 2}

\section{Basis for tenor seven years}
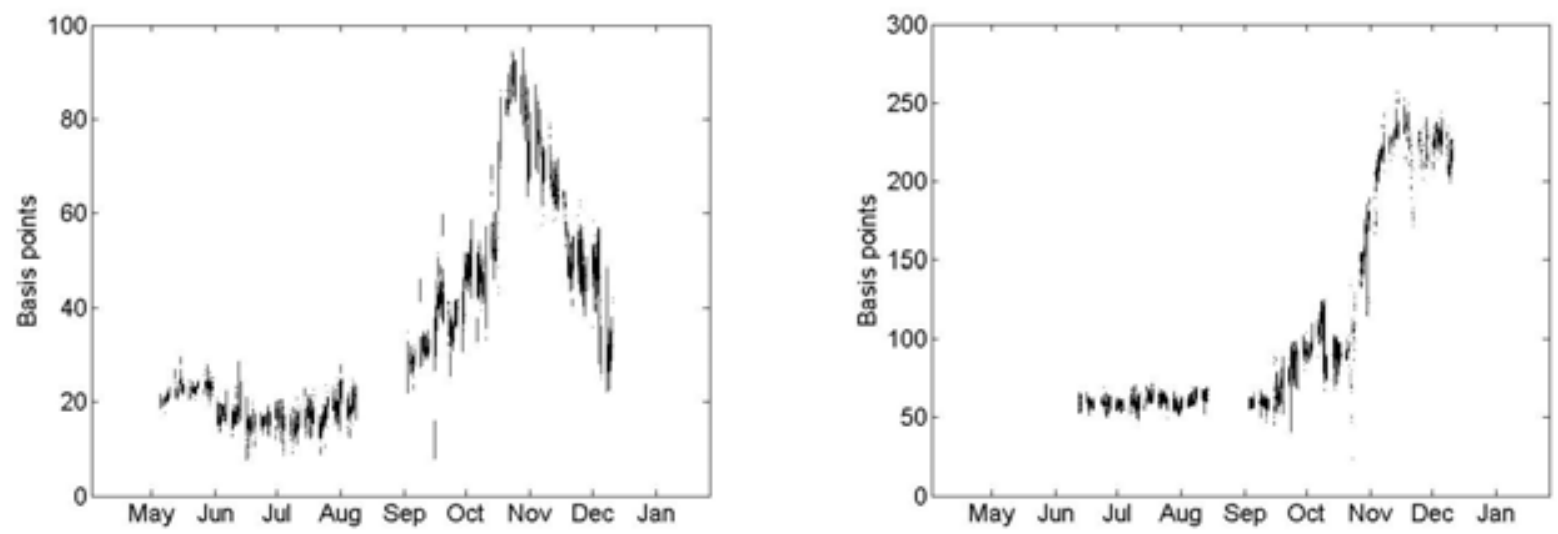
Table 1

Average of difference between swap BEIR and bond BEIR

\begin{tabular}{|c|c|c|}
\hline \multicolumn{3}{|c|}{ Euro area } \\
\hline & \multicolumn{2}{|c|}{ Basis points } \\
\hline 2-year swap-bond BEIR & 37.9 & 45.2 \\
\hline 4-year swap-bond BEIR & 30.7 & 49.2 \\
\hline 5-year swap-bond BEIR & 36.7 & 68.5 \\
\hline 7-year swap-bond BEIR & 23.4 & 55.8 \\
\hline 8-year swap-bond BEIR & 24.2 & 61.5 \\
\hline 12-year swap-bond BEIR & 19.8 & 53.9 \\
\hline \multicolumn{3}{|c|}{ United States } \\
\hline & \multicolumn{2}{|c|}{ Basis points } \\
\hline 2-year swap-bond BEIR & -3.1 & 125.9 \\
\hline 3-year swap-bond BEIR & 14.8 & 147.5 \\
\hline 4-year swap-bond BEIR & 25.0 & 115.6 \\
\hline 5-year swap-bond BEIR & 32.3 & 76.6 \\
\hline 6-year swap-bond BEIR & 64.9 & 147.0 \\
\hline 7-year swap-bond BEIR & 66.2 & 129.7 \\
\hline 8-year swap-bond BEIR & 53.2 & 105.4 \\
\hline 9-year swap-bond BEIR & 48.9 & 92.2 \\
\hline 10-year swap-bond BEIR & 45.5 & 94.9 \\
\hline
\end{tabular}

We performed unit root tests for all time series and could not reject the null at conventional test sizes using the Augmented Dickey Fuller test. We determined the lag order of the unrestricted vector auto regression following the Schwarz information criterion. Since the criterion required at most 15 lags, ie 15 minutes, we suspected that overnight returns did not play a prominent role in our estimations. This would, however, be the case if market prices jumped a lot between market close and opening on the next day. ${ }^{17}$ Yet swaps and bonds are hardly traded outside the peak trading hours ranging from $8 \mathrm{am}$ to $6 \mathrm{pm}$ in the euro area and from 9 am to midnight in the United States, which we fully cover in our sample.

We report Johansen trace statistics for the determination of the number of cointegration vectors in Tables A-8 and A-9 in the Appendix. The pairs of all swap and bond BEIR for all maturities exhibit one cointegration relation and therefore one common trend. As previously discussed, markets price BEIR entirely equally only if the unity cointegration vector $[1,-1]$ applies. Yet swap BEIR nearly always exhibit higher liquidity and risk premia than bond BEIR. To cover this difference, we included a constant in our cointegration vector. In the euro area only shorter maturities, two and four years, comply with the restriction of a common price up to a constant amount. For the United States, this is the case for two, seven, and

17 Re-estimation of the VECM and the Hasbrouck information shares with the overnight returns substituted with the mean return of the following day showed virtually no influence on the parameters. We thank Franziska Peter and Joachim Grammig for performing the estimation using their Gauss procedures. 
eight years. For other (longer) maturities, at least one market exhibits time-varying nontransient factors in its price that might be due to non-stationary liquidity differentials in both markets. ${ }^{18}$

The Hasbrouck information share midpoints show that for tenors of 2-5 years price discovery on inflation expectations is nearly evenly split in the euro area (see Table 2) ${ }^{19}$ Yet the bond market leads as shares are still significantly different from equality. ${ }^{20}$ This changes at longer maturities. Almost no price discovery takes place in the swap market for eight-year BEIR. This result is confirmed by the Gonzalo Granger contributions to the common factor which are reported in the same table. ${ }^{21}$ In contrast to what we see in price discovery studies featuring derivatives and their underlyings (Upper and Werner (2007)) it is not the derivative market that dominates price formation in our study.

Table 2

\section{Contributions to price discovery in the euro area}

\begin{tabular}{|c|c|c||c|c|}
\hline & \multicolumn{2}{|c|}{ Hasbrouck inform. shares } & \multicolumn{2}{c|}{ Gonzalo Granger } \\
& Summer 08 & Autumn 08 & Summer 08 & Autumn 08 \\
\hline \hline 2-year swap BEIR & 0.46 & 0.09 & 0.29 & 0.09 \\
2-year bond BEIR & 0.54 & 0.91 & 0.71 & 0.91 \\
\hline 4-year swap BEIR & 0.44 & 0.05 & 0.32 & 0.08 \\
4-year bond BEIR & 0.56 & 0.95 & 0.68 & 0.92 \\
\hline 5-year swap BEIR & 0.44 & 0.06 & 0.28 & 0.08 \\
5-year bond BEIR & 0.56 & 0.94 & 0.72 & 0.92 \\
\hline 7-year swap BEIR & 0.30 & 0.05 & 0.22 & 0.07 \\
7-year bond BEIR & 0.70 & 0.95 & 0.78 & 0.93 \\
\hline 8-year swap BEIR & 0.09 & 0.04 & 0.08 & 0.05 \\
8-year bond BEIR & 0.91 & 0.96 & 0.92 & 0.95 \\
\hline 12-year swap BEIR & 0.34 & 0.02 & 0.28 & 0.04 \\
12-year bond BEIR & 0.66 & 0.98 & 0.72 & 0.96 \\
\hline
\end{tabular}

Note: Midpoints of Hasbrouck information shares are reported. Lower and upper bounds can be found in Table A-10 in the Appendix. Where appropriate, according to the results in Table A-8, the restriction of a unity vector is imposed.

Since not all time series showed linear trends we did not include them in our cointegration analysis. Nevertheless, once included the results did not change qualitatively See Table A-10 in the Appendix for upper and lower bounds of the Hasbrouck information share measure. Wald tests on the equality of the ratio of adjustment coefficients or the ratio of the $\gamma$ respectively are rejected at conventional test sizes.

21 As discussed before, the divergence of both measures is greater when either the correlation of the residuals or their variances differ significantly. 
Table 3

\section{Contributions to price discovery in the US}

\begin{tabular}{|c|c|c||c|c|}
\hline & \multicolumn{2}{|c|}{ Hasbrouck inform. shares } & \multicolumn{2}{c|}{ Gonzalo Granger } \\
& Summer 08 & Autumn 08 & Summer 08 & Autumn 08 \\
\hline \hline 2-year swap BEIR & 0.27 & & 0.14 & \\
2-year bond BEIR & 0.73 & & 0.86 & \\
\hline 3-year swap BEIR & 0.12 & & 0.06 & \\
3-year bond BEIR & 0.88 & & 0.94 & \\
\hline 4-year swap BEIR & 0.13 & & 0.06 & \\
4-year bond BEIR & 0.87 & & 0.94 & \\
\hline 5-year swap BEIR & 0.11 & 0.07 & 0.04 & 0.04 \\
5-year bond BEIR & 0.89 & 0.93 & 0.96 & 0.96 \\
\hline 6-year swap BEIR & 0.18 & & 0.10 & \\
6-year bond BEIR & 0.92 & & 0.90 & \\
\hline 7-year swap BEIR & 0.09 & 0.08 & 0.02 & 0.03 \\
7-year bond BEIR & 0.91 & 0.92 & 0.98 & 0.97 \\
\hline 8-year swap BEIR & 0.04 & 0.04 & 0.00 & 0.03 \\
8-year bond BEIR & 0.96 & 0.96 & 1.00 & 0.97 \\
\hline 9-year swap BEIR & 0.04 & 0.03 & 0.02 & 0.04 \\
9-year bond BEIR & 0.96 & 0.97 & 0.98 & 0.96 \\
\hline 10-year swap BEIR & 0.04 & 0.04 & 0.01 & 0.02 \\
10-year bond BEIR & 0.96 & 0.96 & 0.99 & 0.98 \\
\hline
\end{tabular}

Note: Hasbrouck midpoints, lower and upper bounds can be found in Table A-11 in the Appendix. Blank spaces indicate no cointegration relation. Where appropriate according to the results in Table A-9 the restriction of a unity vector is imposed.

One interpretation of that result is that especially for longer maturities protection against unexpected inflation rate deviations is virtually only provided by central governments. There is a supply and a demand side to that argument. On the demand side, investors seek longterm protection against inflation and want to keep counterparty risk to a minimum. This cannot be completely eliminated by posting collateral. The valuation underlying the exchange of collateral is a marginal calculation. However, if a large market participant fails, all its counterparties need to hedge their positions. This results in a more than marginal shift in demand or supply and, hence a price movement that is not covered by the collateral posted. Note that this argument draws neither on variations in risk-aversion nor on transaction costs. Nevertheless, transaction costs may be relevant as even in a highly developed system it takes some time to negotiate new contracts. After the default of Lehman Brothers some banks needed several weeks to find counterparties to hedge all their open swap positions. Any price movement during this time is naturally not covered by collateral. This remaining counterparty or default-to-replacement risk may lead market participants to prefer risk-free government bonds. On the supply side it is reasonable to assume that the banking sector's aggregate supply of inflation-indexed claims is zero. This is because banks typically only intermediate between different clients. Yet inflation supply comes from the private sector, too. Especially for the UK it is well documented that public private partnerships are selling 
inflation into the market. ${ }^{22}$ However, these privately supplied cash flows are very untransparent compared to indexed government bonds. Hence financial institutions, brokers and corporate treasurers that act as inflation-takers on the swap market have a reason to be cagey when taking inflation risk in their books that is priced differently to the government bond market.

We motivated our use of an US dataset with the different structure of markets for tradable inflation expectations in the euro area and the United States. The prior of a larger and more liquid inflation-linked bond market over a less established inflation swap market can be recovered in the results for the United States. Hasbrouck information share midpoints and Gonzalo Granger contributions show a clear lead of the bond market in our baseline scenario (see Table 3). Only for the shortest maturity does the swap market contribute less than one third to the price discovery process. Most likely the volume of the respective market does play a role in determining where price discovery takes place.

\subsection{Price discovery in times of extreme financial crisis}

In Autumn 2008 a fully-fledged financial crisis propagated through the financial system and the real economy. It left inter alia the United States and the euro area in a recession at the year-end. The turmoil in the financial markets was accompanied by larger amplitudes for price changes of financial instruments. The increased variability showed up in both the bond and the swap markets (see Tables A-6 and A-7 in the Appendix). Standard deviations for bond and swap prices nearly quadrupled in the euro area and blew up tenfold in the US. Furthermore, the price distribution exhibited a significantly lower kurtosis, eg prices were more scattered away from the mean. The higher variability was more contained for longer maturities as it was primarily the short-term markets that were persistently disrupted during the financial crisis. The mean of BEIR decreased considerably for all maturities and it even went negative for some tenors. Again the development was more pronounced in the United States. The mean of the BEIR decreased far more in the United States from partly over 3 percentage points to negative values of partly over 1 percentage point for short to medium maturities. The lower inflation expectations incorporated in the BEIR were in line with an upcoming negative economic outlook and falling energy and commodity prices which brought down actual inflation rates and inflation expectations in surveys. Nevertheless it was partly driven by the liquidity drain stemming from the withdrawal of risky assets and the search for highest-quality collateral which most affected nominal government bonds. The liquidity differential between nominal and real government bonds widened considerably and bond BEIR fell accordingly.

The crisis involved a significant increase of risk aversion on the part of investors and consequently affected various financial instruments and markets differently. The difference between swap and bond BEIR, the basis, increased considerably after September 2008 (see Table 1). The wedge between the swap and the bond market in the United States broadened up to the point where one would expect that neither market would any longer exhibit a cointegration relationship. At that stage, default-to-replacement risk had become manifest for all market participants.

Still, the question remains as to why the elevated basis was not arbitraged away. Three factors might have hampered the smoothing-out of price differences: increased transaction costs, liquidity-constrained dealers and interest rate uncertainty. First, trades have become more costly due to increased bid/ask spreads. The increase was pronounced with inflation

22 This could be traffic infrastructure projects or hospitals. Many are regulated to adjust their prices by the inflation rate or a share of their contract payments is directly inflation-linked, typically the remuneration for operating expenses. See Grath and Windle (2006). 
swaps in particular (see Graph 3). Even though the mean of the overall tight bid/ask spread was higher by only half a basis point in our crisis sample, variation picked up dramatically. A bid/ask spread of 20 basis points, which was not unusual in November and December for some trading hours, made relative value trades prohibitively costly. Furthermore, spreads went up for bond trading as well. On the bond market the spread increase was more pronounced for inflation-linked than for nominal bonds. ${ }^{23}$ While the absolute rise of the spread was small in numbers it was twice as high for the inflation-indexed as for the nominal bond market. Accordingly, trading volumes of inflation-linked bonds on electronic platforms declined, in the case of the European MTS system by more than 60\%. For the TIPS market, it was reported that the spread more than doubled amid a reluctance to trade (Madar, Rodrigues and Steinberg (2009)). This development amplified the liquidity differential between real and nominal bonds. Bond BEIR, the difference between nominal and real bonds, went down further. Second, some of the most active traders, eg banks and hedge funds, faced liquidity and financing constraints. With a diminishing capital basis caused by huge write-offs, banks were forced to reduce both portfolio holdings and capital allocated to their trading desks. Hedge funds, a standard class of arbitrageurs, faced significant withdrawals from their customers after reporting poor performance. Furthermore, banks were less willing to finance highly leveraged operations. Thus, banks, hedge funds and other dealers were hindered from investing in cheap bonds and reselling the inflation-linked cash flow in a disturbed swap market. Third, increased interest rate uncertainty might also have hampered gap-offsetting trades. This is because it became more probable that rates would alter significantly during the transaction time needed to initiate, calculate, fund and execute an arbitrage deal. Yet it was not just demand that dried up considerably. The supply side suffered comparably since fewer people were willing to pay inflation or long-end rates.

\section{Graph 3}

\section{Bid/ask spread for seven-year inflation swaps}

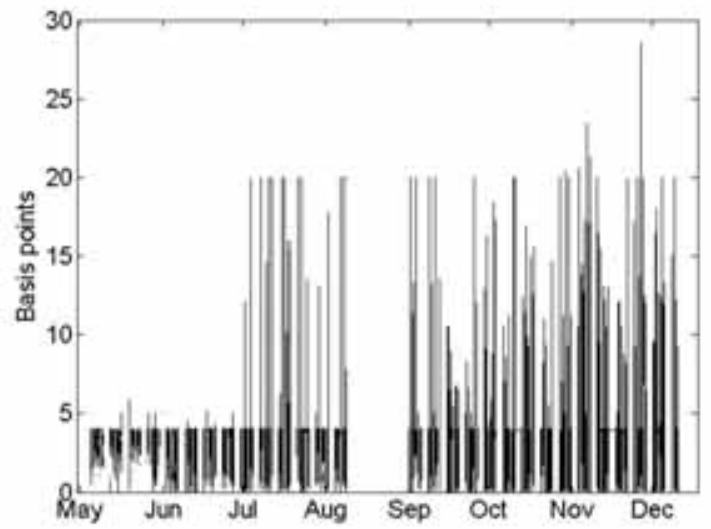

(a) Euro area

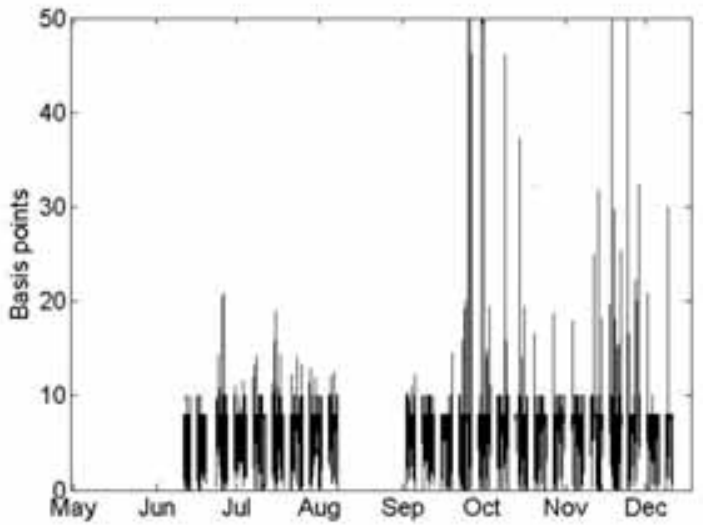

(b) US

Not surprisingly the disturbances affected the pricing of different financial market instruments differently. ${ }^{24}$ Price discovery changed significantly; in fact, it almost shut down on the swap

23 Data from Bloomberg show that, for one big trader, spreads on linkers quadrupled whereas the ones for nominal government bonds only doubled in the Autumn as compared with the first half of the year.

24 We performed unit root tests for all series. The number of lags recommended by the Schwarz information criterion did not exceed 15 or 22 lags where a number of intermediate lags were excluded. Johanson trace statistics for the number of cointegration vectors are reported in Table A-8 in the Appendix. 
market from September to December 2008 in the euro area (see Table 2). ${ }^{25}$ In the shortest maturity segment just under one tenth of information relevant for pricing was first processed in the swap market. For all other maturities, pricing virtually only occurred on the bond market. Likelihood ratio tests of the variables for the cointegration vector showed weak exogeneity for bond BEIR with maturities above two years. This adds to the interpretation that in the crisis period the swap market has become nearly an appendix to the government bond market when it comes to price inflation expectations.

What happened in the United States in the autumn of 2008 can be depicted as the collapse of an integrated market for traded inflation expectations. Technically we were not able to find a cointegration relation between the swap and the bond market for maturities of two, three, four, and six years (see Table A-9 in the Appendix). Economically speaking, arbitrage did not prevent markets from developing in completely different directions. The first explanation for this is the increase in transaction costs due to liquidity and financial constraints. This led to a downturn in trades and, for the inflation swap market, even the daily number of quotes decreased dramatically for shorter maturities (see Graph 4). Secondly, a feature that can be seen as unique for the United States is that the pronounced deflationary expectations hampered relative value trades in BEIR. Inflation-linked bonds safeguard investors against deflationary deductions, which are above the coupon payments since the principal is always repaid at $100 \%$ or more. This feature only becomes relevant in the case of extreme deflation since the embedded option is far out of the money in normal times. However, in the extreme crisis period of autumn 2008, it is not unreasonable to believe that investors actually assigned a positive value to this option. Furthermore, the liquidity differential between nominal and real US bonds also widened substantially and therefore led to lower bond BEIR.

Graph 4

US inflation swaps: number of daily quotes, tenor two years

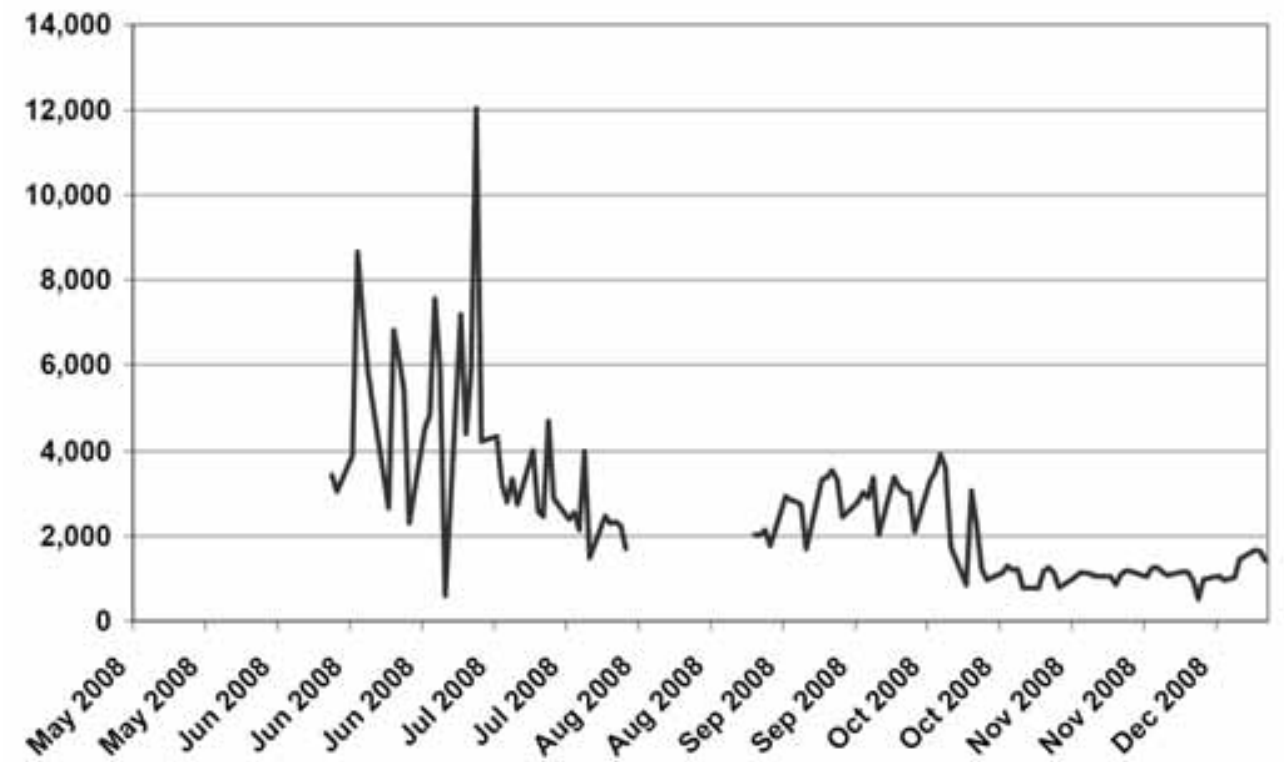

For maturities of five years, seven years and above we still found a cointegration relation and the information shares showed a complete concentration of the price discovery on the 
government bond market. Thus, the declining confidence of investors hindered the trade of financial claims not only in the short-term money market segment but in longer-term markets as well. Only the safest instrument, government bonds, still seemed to be acceptable to investors.

\subsection{Price discovery with forward rates}

The swap and the bond market are affected by idiosyncratic liquidity and market risk and market-specific demand factors. Therefore it might be helpful to look at cointegration and price discovery for BEIR forward rates derived from BEIR spot rates. As long as the marketspecific factors influence all maturities to the same extent, they cancel out when computing forward rates. We calculated five-year forwards starting in two years and starting in five or seven years for both markets and both periods. The series turned out to be stationary in the euro area in the Summer sample, so that no cointegration analysis was executed. For the Autumn period, we calculated Hasbrouck information shares and Gonzalo-Granger contributions to the common factor. For the five-year forward starting in two years, both measures were slightly higher than those for the five-year spot rate in the euro area. Nevertheless the swap market accounted for less than one fifth of price discovery. This is far lower than the information shares computed using the spot rate in the Summer period. This corroborates our interpretation that the crisis infected the short-term segment of the market differently from long-end rates. Furthermore, it shows that apart from idiosyncratic factors prevailing on both markets, the government bond market clearly dominates price discovery for traded long-term inflation expectations.

Forward BEIR from US data showed that price discovery was even in the baseline scenario quantitatively more concentrated on the bond market. For the crisis sample we found a cointegration relationship among the five-year forward bond and swap BEIR starting in two and five years. ${ }^{26}$ This might imply that what broke the cointegration relation is contained in liquidity differentials across maturities of the same market.

\section{Conclusions}

We analyse the price discovery for BEIR by using a high-frequency dataset for inflationindexed as well as nominal government bonds and inflation swaps. News affecting inflation expectations incorporated in the BEIR are processed slightly more quickly on bond markets for maturities up to five years in the euro area. For longer maturities, bond markets increasingly lead the price discovery process. These results are somewhat dependent on the structure, ie the volume and liquidity of the respective markets. It is in the United States, where the TIPS market is large in absolute volume and compared to overall Treasury issuance, that the bond market clearly determines price formation over all time horizons. This is consistent with the notion that even full collateralisation does not completely eliminate counterparty risk. The default-to-replacement risk remains: collateral is valued at the margin and does not cover the time to re-enter positions after the default of a contract party.

During the autumn of 2008, the growing turmoil in the financial markets seriously disturbed pricing in financial markets worldwide. Price discovery ceased to take place in the swap market. This illustrates the severe dysfunction of the normally smooth working derivative market especially for short to medium maturities. Widening bid/ask spreads - more

26 As a caveat, note that unit root tests with forward swap rates are rejected in the majority of cases which is not surprising as forward rates are calculated as differences of spot rates. 
pronounced with derivatives - hampered arbitrage between the bond and the swap market. BEIR were therefore more driven apart than during our baseline sample in Summer 2008. Disruptions coming from the short end of the market even led to a collapse of the integration of the two US markets. Whereas heightened risk aversion generally obstructed trades in financial markets, contributions to price formation concentrated much more on the safest financial instrument, government bonds. Thus, even though in times of severe financial stress swap curves often displayed a much smoother picture, bond BEIR must not be omitted from economic analysis.

In general, BEIR are priced higher on the swap market. We assign this mostly to liquidity and risk premia. Furthermore, the difference between instruments on both markets is not constant but displays time variation. We propose the default-to-replacement risk as one of the features driving this time variability. Embedded put options in inflation-linked bonds, which safeguard against a loss in an extreme deflationary setting, are another explanation for time-variable swap and bond BEIR differences. Since idiosyncratic liquidity and risk premia are difficult to quantify, a promising starting point for further research might be to relate changes in the liquidity premia to aggregate liquidity conditions following Adrian and Shin (2008). 


\section{Appendix}

Figure A-1

Break-even inflation rate from bonds and swaps for tenor of seven years

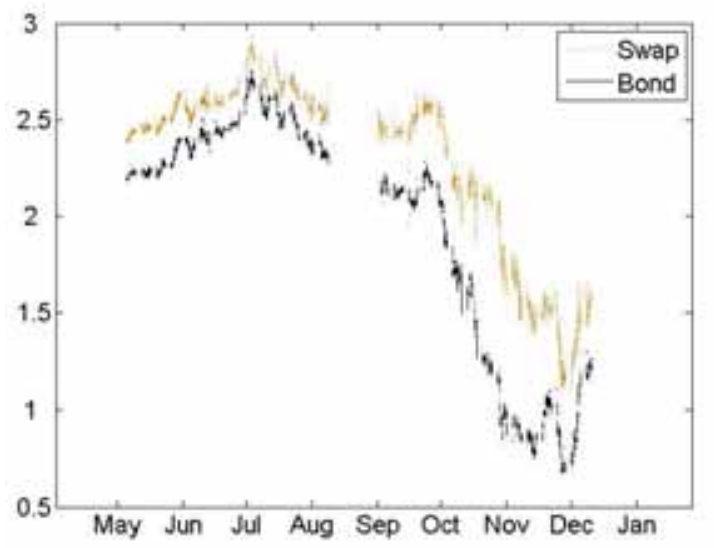

(a) Euro area

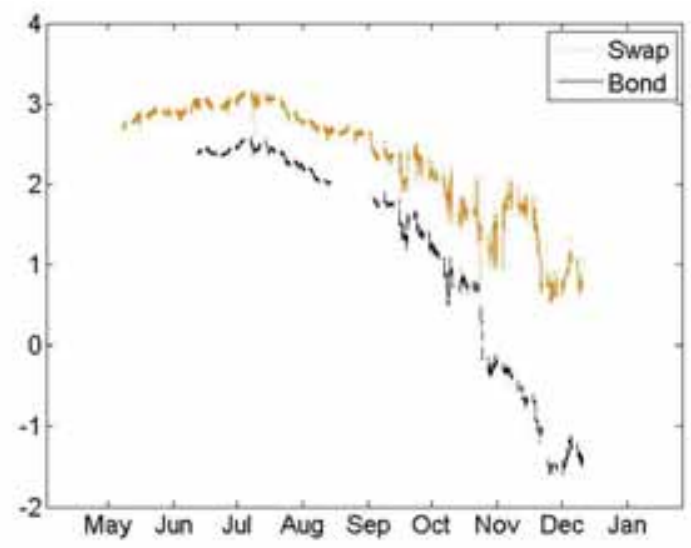

(b) US 
Table A-1

\section{List of euro area bonds}

\begin{tabular}{|c|c|c|c|c|c|}
\hline Tenor & ISIN & Coupon & Type & First Issue & Maturity \\
\hline \multirow[t]{2}{*}{2 years } & FR0108664055 & 1.25 & real & 20 Apr 2006 & 25 Jul 2010 \\
\hline & FR0107674006 & 2.50 & nominal & 16 Jun 2005 & 12 Jul 2010 \\
\hline \multirow[t]{2}{*}{4 years } & FR0000188013 & 3.00 & real & 25 .Jul 2001 & 25 Jul 2012 \\
\hline & FR0000188328 & 5.00 & nominal & $25 \mathrm{Apr} 2001$ & 25 Apr 2012 \\
\hline \multirow[t]{2}{*}{5 years } & DE0001030518 & 2.25 & real & 24 Oct 2007 & 15 Apr 2013 \\
\hline & DE0001135234 & 3.75 & nominal & 04 Jul 2003 & 04 Jul 2013 \\
\hline \multirow[t]{2}{*}{7 years } & FR0010135525 & 1.60 & real & 25 Jul 2004 & 25 Jul 2015 \\
\hline & FR0010163543 & 3.50 & nominal & 25 Apr 2004 & 25 Apr 2015 \\
\hline \multirow[t]{2}{*}{8 years } & DE0001030500 & 1.50 & real & 08 Mar 2006 & 15 Apr 2016 \\
\hline & DE0001135291 & 3.50 & nominal & 23 Nov 2005 & 04 Jan 2016 \\
\hline \multirow[t]{2}{*}{12 years } & FR0010050559 & 2.25 & real & 25 Jul 2003 & 25 Jul 2020 \\
\hline & FR0010192997 & 3.75 & nominal & 04 May 2005 & $25 \mathrm{Apr} 2021$ \\
\hline
\end{tabular}

Notes: Real bonds indexed to the harmonised euro area HICP ex-tobacco.

Indexation month for French paper is April, for German January.

Table A-2

\section{List of US nominal bonds}

\begin{tabular}{r|rlll} 
Tenor & ISIN & Coupon & First Issue & Maturity \\
\hline \hline 2 years & US912828CX62 & 3.375 & $10 / 15 / 2004$ & $10 / 15 / 2009$ \\
3 years & US912828FD71 & 4.875 & $5 / 1 / 2006$ & $4 / 30 / 2011$ \\
4 years & US912828GQ75 & 4.5 & $4 / 30 / 2007$ & $4 / 30 / 2012$ \\
5 years & US912828HY90 & 3.125 & $4 / 30 / 2008$ & $4 / 30 / 2013$ \\
6 years & US912828CT50 & 4.25 & $8 / 16 / 2004$ & $8 / 15 / 2014$ \\
7 years & US912828EE63 & 4.25 & $8 / 15 / 2005$ & $8 / 15 / 2015$ \\
8 years & US912828FQ84 & 4.875 & $8 / 15 / 2006$ & $8 / 15 / 2016$ \\
9 years & US912828HA15 & 4.75 & $8 / 15 / 2007$ & $8 / 15 / 2017$ \\
10 years & US912828HR40 & 3.5 & $2 / 15 / 2008$ & $2 / 15 / 2018$ \\
\hline
\end{tabular}

Notes: US bonds pay interest semiannually. 
Table A-3

\section{List of US inflation-indexed bonds (TIPS)}

\begin{tabular}{r|rlll} 
Tenor & ISIN & Coupon & First Issue & Maturity \\
\hline \hline 2 years & US912828CZ11 & 0.875 & $10 / 29 / 2004$ & $4 / 15 / 2010$ \\
3 years & US912828FB16 & 2.375 & $4 / 28 / 2006$ & $4 / 15 / 2011$ \\
4 years & US912828GN45 & 2.0 & $4 / 30 / 2007$ & $4 / 15 / 2012$ \\
5 years & US912828HW35 & 0.625 & $4 / 30 / 2008$ & $4 / 15 / 2013$ \\
6 years & US912828CP39 & 2.0 & $7 / 15 / 2004$ & $7 / 15 / 2014$ \\
7 years & US912828EA42 & 1.875 & $7 / 15 / 2005$ & $7 / 15 / 2015$ \\
8 years & US912828FL97 & 2.5 & $7 / 17 / 2006$ & $7 / 15 / 2016$ \\
9 years & US912828GX27 & 2.625 & $7 / 16 / 2007$ & $7 / 15 / 2017$ \\
10 years & US912828HN36 & 1.625 & $1 / 15 / 2008$ & $1 / 15 / 2018$ \\
\hline
\end{tabular}

Notes: TIPS are indexed to the CPI-U and pay interest semiannually.

Table A-4

Number of observations by instrument: euro area

\begin{tabular}{r|rrr} 
tenor & nominal bond & real bond & inflation swap \\
\hline \hline 2 years & 32,655 & 27,488 & 72,002 \\
4 years & 49,024 & 45,241 & 73,410 \\
5 years & 57,452 & 18,733 & 73,312 \\
7 years & 56,934 & 42,337 & 73,850 \\
8 years & 63,017 & 12,617 & 73,942 \\
12 years & 55,782 & 38,973 & 72,213 \\
& & & \\
total & 314,864 & 185,389 & 438,729 \\
\hline
\end{tabular}

Notes: Number of bid/ask pairs. 5 May to 8 December 2008. 
Table A-5

Number of observations by instrument: United States

\begin{tabular}{r|rrr} 
tenor & nominal bond & real bond & inflation swap \\
\hline \hline 2 years & 26,798 & 17,831 & 95,349 \\
3 years & 46,858 & 25,651 & 94,599 \\
4 years & 55,833 & 29,308 & 95,463 \\
5 years & 58,825 & 37,561 & 91,589 \\
6 years & 64,525 & 36,599 & 98,166 \\
7 years & 62,793 & 35,823 & 94,420 \\
8 years & 66,964 & 43,040 & 98,673 \\
9 years & 69,090 & 47,661 & 90,027 \\
10 years & 68,935 & 51,196 & 99,973 \\
& & & \\
total & 520,621 & 324,670 & 858,259 \\
\hline
\end{tabular}

Notes: Number of bid/ask pairs. 12 June to 9 December 2008.

Table A-6

Descriptive statistics of break-even inflation rates in the euro area

\begin{tabular}{|r|c|c|c||c|c|c|}
\hline & \multicolumn{3}{|c|}{ Pre-crisis/ Summer 08 } & \multicolumn{3}{c|}{ Crisis/ Autumn 08 } \\
& Mean & Std.dev. & Kurtosis & Mean & Std.dev. & Kurtosis \\
\hline \hline 2-year bond BEIR & 2.35 & 0.24 & 2.54 & 0.91 & 0.90 & 1.40 \\
\hline 4-year bond BEIR & 2,34 & 0.17 & 2.58 & 1.17 & 0.75 & 1.36 \\
\hline 5-year bond BEIR & 2.25 & 0.16 & 2.53 & 1.11 & 0.71 & 1.31 \\
\hline 7-year bond BEIR & 2.36 & 0.13 & 2.34 & 1.41 & 0.53 & 1.38 \\
\hline 8-year bond BEIR & 2.34 & 0.12 & 2.58 & 1.43 & 0.53 & 1.41 \\
\hline 12-year bond BEIR & 2.39 & 0.11 & 2.41 & 1.70 & 0.40 & 1.67 \\
\hline \hline 2-year swap BEIR & 2.73 & 0.23 & 2.56 & 1.36 & 0.82 & 1.43 \\
\hline 4-year swap BEIR & 2.65 & 0.16 & 2.69 & 1.67 & 0.67 & 1.52 \\
\hline 5-year swap BEIR & 2.62 & 0.14 & 2.61 & 1.79 & 0.59 & 1.55 \\
\hline 7-year swap BEIR & 2.59 & 0.11 & 2.67 & 1.98 & 0.45 & 1.60 \\
\hline 8-year swap BEIR & 2.58 & 0.10 & 2.61 & 2.05 & 0.39 & 1.62 \\
\hline 12-year swap BEIR & 2.59 & 0.09 & 2.06 & 2.24 & 0.28 & 1.85 \\
\hline
\end{tabular}


Table A-7

Descriptive statistics of break-even inflation rates in the United States

\begin{tabular}{|r|c|c|c||c|c|c|}
\hline & \multicolumn{3}{|c|}{ Pre-crisis/ Summer 08 } & \multicolumn{3}{c|}{ Crisis/ Autumn 08 } \\
& Mean & Std.dev. & Kurtosis & Mean & Std.dev. & Kurtosis \\
\hline \hline 2-year bond BEIR & 3.07 & 0.26 & 1.74 & -1.75 & 2.77 & 1.51 \\
\hline 3-year bond BEIR & 2.87 & 0.20 & 1.68 & -1.22 & 2.11 & 1.48 \\
\hline 4-year bond BEIR & 2.75 & 0.20 & 1.68 & -0.26 & 1.46 & 1.48 \\
\hline 5-year bond BEIR & 2.67 & 0.19 & 1.76 & 0.49 & 0.95 & 1.51 \\
\hline 6-year bond BEIR & 2.33 & 0.17 & 1.98 & -0.05 & 1,23 & 1.56 \\
\hline 7-year bond BEIR & 2.30 & 0.15 & 2.56 & 0.26 & 1.08 & 1.60 \\
\hline 8-year bond BEIR & 2.40 & 0.14 & 2.55 & 0.62 & 0.97 & 1.66 \\
\hline 9-year bond BEIR & 2.43 & 0.11 & 2.54 & 0.90 & 0.75 & 1.80 \\
\hline 10-year bond BEIR & 2.47 & 0.12 & 3.00 & 1.01 & 0.60 & 1.97 \\
\hline \hline 2-year swap BEIR & 3.04 & 0.33 & 1.96 & -0.49 & 1.64 & 1.58 \\
\hline 3-year swap BEIR & 3.03 & 0.30 & 1.90 & 0.25 & 1.27 & 1.64 \\
\hline 4-year swap BEIR & 3.00 & 0.26 & 1.88 & 0.89 & 0.90 & 1.92 \\
\hline 5-year swap BEIR & 3.00 & 0.22 & 1.96 & 1.26 & 0.77 & 2.34 \\
\hline 6-year swap BEIR & 2.98 & 0.20 & 2.02 & 1.41 & 0.66 & 2.06 \\
\hline 7-year swap BEIR & 2.96 & 0.17 & 2.07 & 1.56 & 0.58 & 2.03 \\
\hline 8-year swap BEIR & 2.93 & 0.14 & 2.22 & 1.67 & 0.53 & 2.15 \\
\hline 9-year swap BEIR & 2.92 & 0.12 & 2.44 & 1.82 & 0.46 & 2.29 \\
\hline 10-year swap BEIR & 2.93 & 0.10 & 2.36 & 1.96 & 0.38 & 2.38 \\
\hline
\end{tabular}


Table A-8

\section{Long-run relation between swap BEIR and bond BEIR in the euro area}

\begin{tabular}{|c|c|c|c|}
\hline & \multicolumn{3}{|c|}{ Pre-crisis/Summer 08 } \\
& \# coint. vectors (cv) & Restriction on cv \\
& None & At most 1 & $(1,-1, c)$ \\
\hline \hline 2-year swap-bond BEIR & $66.91^{* * *}$ & 2.59 & 1.18 \\
\hline 4-year swap-bond BEIR & $111.07^{* * *}$ & 3.05 & $2.85^{*}$ \\
\hline 5-year swap-bond BEIR & $97.61^{* * *}$ & 2.66 & $22.43^{* * *}$ \\
\hline 7-year swap-bond BEIR & $166.85^{* * *}$ & 3.41 & $67.49^{* * *}$ \\
\hline 8-year swap-bond BEIR & $187.65^{* * *}$ & 3.31 & $66.10^{* * *}$ \\
\hline 12-year swap-bond BEIR & $61.64^{* * *}$ & 5.23 & $16.65^{* * *}$ \\
\hline \hline & \multicolumn{3}{|c|}{ Crisis/ Autumn 08 } \\
\hline \hline 2-year swap-bond BEIR & $151.93^{* * *}$ & 2.93 & Restriction on cv \\
\hline 4-year swap-bond BEIR & $44.94^{* * *}$ & 3.09 & $(1,-1, c)$ \\
\hline 5-year swap-bond BEIR & $23.88^{* * *}$ & 3.47 & $60.71^{* * *}$ \\
\hline 7-year swap-bond BEIR & $23.27^{* * *}$ & 2.97 & $11.39^{* * *}$ \\
\hline 8-year swap-bond BEIR & $35.19^{* * *}$ & 3.36 & $7.46^{* * *}$ \\
\hline 12-year swap-bond BEIR & $46.67^{* * *}$ & 3.13 & $5.19^{* *}$ \\
\hline
\end{tabular}

Rejections of the null at the $10 \%, 5 \%$, or $1 \%$ level is indicated by a superscript *,*, or *** respectively. 
Table A-9

Long-run relation between swap BEIR and bond BEIR in the United States

\begin{tabular}{|c|c|c|c|}
\hline & \multicolumn{3}{|c|}{ Pre-crisis/ Summer 08 } \\
& \# coint. vectors (cv) & Restriction on cv \\
& None & At most 1 & $(1,-1$, c) \\
\hline \hline 2-year swap-bond BEIR & $34.23^{* * *}$ & 0.73 & 1.98 \\
\hline 3-year swap-bond BEIR & $87.77^{* * *}$ & 0.96 & $16.53^{* * *}$ \\
\hline 4-year swap-bond BEIR & $90.90^{* * *}$ & 0.75 & $29.07^{* * *}$ \\
\hline 5-year swap-bond BEIR & $122.79^{* * *}$ & 0.94 & $26.83^{* * *}$ \\
\hline 6-year swap-bond BEIR & $179.55^{* * *}$ & 1.07 & $71.53^{* * *}$ \\
\hline 7-year swap-bond BEIR & $139.04^{* * *}$ & 1.61 & $44.11^{* * *}$ \\
\hline 8-year swap-bond BEIR & $122.31^{* * *}$ & 2.15 & 0.04 \\
\hline 9-year swap-bond BEIR & $128.65^{* * *}$ & 1.56 & 0.48 \\
\hline 10-year swap-bond BEIR & $145.78^{* * *}$ & 2.10 & $19.13^{* * *}$ \\
\hline \hline & \multicolumn{3}{|c|}{ Crisis/ Autumn 08} \\
& $\#$ coint. vectors (cv) & Restriction on cv \\
\hline \hline 2-year swap-bond BEIR & $119.73^{* * *}$ & $12.05^{* * *}$ & $(1,-1, c)$ \\
\hline 3-year swap-bond BEIR & $181.45^{* * *}$ & $31.88^{* * *}$ & \\
\hline 4-year swap-bond BEIR & $54.65^{* * *}$ & $9.21^{* *}$ & \\
\hline 5-year swap-bond BEIR & $25.30^{* * *}$ & 7.34 & $4.40^{* *}$ \\
\hline 6-year swap-bond BEIR & $52.28^{* * *}$ & $10.76^{* *}$ & \\
\hline 7-year swap-bond BEIR & $61.18^{* * *}$ & 6.94 & $44.68^{* * *}$ \\
\hline 8-year swap-bond BEIR & $56.14^{* * *}$ & 7.71 & $40.39^{* * *}$ \\
\hline 9-year swap-bond BEIR & $41.20^{* * *}$ & 7.28 & $22.89^{* * *}$ \\
\hline 10-year swap-bond BEIR & $41.89^{* * *}$ & 2.70 & $24.92^{* * *}$ \\
\hline
\end{tabular}

Rejections of the null at the $10 \%, 5 \%$, or $1 \%$ level is indicated by a superscript $*, * \star$, or ${ }^{\star \star \star}$ respectively. 
Table A-10

Bounds on Hasbrouck information shares in the euro area

\begin{tabular}{|c|c|c||c|c|}
\hline & \multicolumn{2}{|c|}{ Summer } & \multicolumn{2}{c|}{ Autumn } \\
& Lower & Upper & Lower & Upper \\
\hline \hline 2-year swap BEIR & 0.44 & 0.47 & 0.08 & 0.11 \\
2-year bond BEIR & 0.53 & 0.56 & 0.89 & 0.92 \\
\hline 4-year swap BEIR & 0.42 & 0.47 & 0.03 & 0.07 \\
4-year bond BEIR & 0.54 & 0.58 & 0.93 & 0.97 \\
\hline 5-year swap BEIR & 0.41 & 0.46 & 0.04 & 0.08 \\
5-year bond BEIR & 0.54 & 0.59 & 0.92 & 0.96 \\
\hline 7-year swap BEIR & 0.27 & 0.32 & 0.03 & 0.06 \\
7-year bond BEIR & 0.68 & 0.73 & 0.93 & 0.97 \\
\hline 8-year swap BEIR & 0.08 & 0.10 & 0.03 & 0.06 \\
8-year bond BEIR & 0.90 & 0.92 & 0.94 & 0.98 \\
\hline 12-year swap BEIR & 0.29 & 0.30 & 0.01 & 0.03 \\
12-year bond BEIR & 0.63 & 0.70 & 0.97 & 0.99 \\
\hline
\end{tabular}

Note: Where appropriate, according to the results in Table A-8, the restriction of a unity vector is imposed. 
Table A-11

Bounds on Hasbrouck information shares in the United States

\begin{tabular}{|c|c|c||c|c|}
\hline & \multicolumn{2}{|c|}{ Summer } & \multicolumn{2}{c|}{ Autumn } \\
& Lower & Upper & Lower & Upper \\
\hline \hline 2-year swap BEIR & 0.27 & 0.27 & & \\
2-year bond BEIR & 0.73 & 0.73 & & \\
\hline 3-year swap BEIR & 0.44 & 0.47 & 0.08 & 0.11 \\
3-year bond BEIR & 0.11 & 0.12 & & \\
\hline 4-year swap BEIR & 0.88 & 0.89 & & \\
4-year bond BEIR & 0.13 & 0.13 & & \\
\hline 5-year swap BEIR & 0.86 & 0.87 & 0.03 & 0.04 \\
5-year bond BEIR & 0.10 & 0.11 & 0.96 & 0.97 \\
\hline 6-year swap BEIR & 0.18 & 0.19 & & \\
6-year bond BEIR & 0.81 & 0.82 & & \\
\hline 7-year swap BEIR & 0.09 & 0.09 & 0.02 & 0.02 \\
7-year bond BEIR & 0.91 & 0.91 & 0.98 & 0.98 \\
\hline 8-year swap BEIR & 0.04 & 0.04 & 0.00 & 0.00 \\
8-year bond BEIR & 0.96 & 0.96 & 1.00 & 1.00 \\
\hline 9-year swap BEIR & 0.04 & 0.04 & 0.01 & 0.02 \\
9-year bond BEIR & 0.96 & 0.96 & 0.98 & 0.99 \\
\hline 10-year swap BEIR & 0.04 & 0.04 & 0.00 & 0.01 \\
10-year bond BEIR & 0.96 & 0.96 & 1.00 & 0.99 \\
\hline
\end{tabular}

Note: Where appropriate, according to the results in Table A-9, the restriction of a unity vector is imposed. 


\section{References}

Adrian, T and H Shin (2008): "Financial intermediary leverage and value-at-risk", Federal Reserve Bank of New York Staff Reports, no 338.

Armann, V, B Benaben and B Lambert (2005): "Inflation flows and investment strategies", in Inflation-linked products - A guide for investors and asset \& liability managers, B Benaben (ed), pp 65-116, Riskbooks.

Baillie, R, G Bootha, Y Tse and T Zabotinac (2002): "Price discovery and common factor models", Journal of Financial Markets, 5, pp 309-21.

Blanco, R, S Brennan and I Marsh (2005): "An empirical analysis of the dynamic relation between investment-grade bonds and credit default swaps", Journal of Finance, vol 60, no 5, pp 2255-81.

Buraschi, A and D Menini (2002): "Liquidity risk and specialness", Journal of Financial Economics, vol 64, 243-84.

Campbell, J and R Shiller (1996): "A scorecard for indexed government debt", in National Bureau of Economic Research Macroeconomics Annual, B Bernanke and J Rotermberg (eds), pp 155-97, MIT Press.

Campbell, J, R Shiller and L Viceira (2009): "Understanding inflation-indexed bond markets", NBER Working Paper, no 15014.

Deacon, M, A Derry and D Mirfendereski (2004): Inflation-indexed securities, John Wiley, second edition.

Doetz, N (2007): "Time-varying contributions by the corporate bond and CDS markets to credit risk price discovery", Deutsche Bundesbank Discussion Paper Series 2: Banking and Financial Studies, no 8.

Eijsing, J, J Garcia and T. Werner (2007): "The term structure of euro area break-even inflation rates - the impact of seasonality", ECB Working Paper Series, no 830.

Engle, R and C Granger (1987): "Cointegration, and error correction: representation, estimation, and testing", Econometrica, vol 55, pp 987-1007.

European Central Bank (2006a): "Measures of inflation expectations in the euro area", ECB Monthly Bulletin, July, pp 59-68.

(2006b): "MOC Monitoring Working Group: Treasury inflation-protected bonds and inflation swaps as tools to monitor inflation expectations", mimeo.

Gonzalo, J and C Granger (1995): "Estimation of common long memory components in cointegrated systems", Journal of Business \& Economic Statistics, vol 13, pp 27-36.

Grammig, J and F Peter (2008): "International price discovery in the presence of market microstructure effects", mimeo, Tübingen University.

Grath, G and R Windle (2006): "Recent developments in sterling inflation-linked markets", Bank of England Quarterly Bulletin, vol 46, no 4, pp 24-34.

Hakkio, C and M Rush (1991): "Cointegration: how short is the long run?", Journal of International Money and Finance, vol 10, pp 571-81.

Hasbrouck, J (1995): "One security, many markets: determining the contributions to price discovery", Journal of Finance, vol 50, pp 1175-99.

Hurd, M and J Relleen (2006): "New information from inflation swaps and index-linked bonds", Bank of England Quarterly Bulletin, vol 46, no 1, pp 386-96.

International Swaps and Derivatives Association (2005): 2005 ISDA Collateral guidelines. (2008): ISDA Margin survey 2008. 
Kerkhof, J (2005): “Inflation derivatives explained”, Lehman Brothers.

Kim, D and J Wright (2005): "An arbitrage-free three-factor term structure model and the recent behavior of long-term yields and distant-horizon forward rates", Federal Reserve Board Discussion Paper, no 33.

Liu, J, F Longstaff and R Mandell (2006): "The market price of risk in interest rate swaps: the roles of default and liquidity risks", Journal of Business, vol 79, no 5, pp 2337-59.

Madar, L, A Rodrigues and M Steinberg (2009): "The impact of news on the term structure of break-even inflation", available at Social Science Research Network (SSRN):

http://papers.ssrn.com/sol3/papers.cfm?abstract_id=1343687.

Mizrach, B and C Neely (2005): "Information shares in the U.S. treasury market", Federal Reserve Bank of St Louis Working Paper, no 2005-07E.

Peat, T and R Segregeti (2008): "Inflation derivatives. A user guide," Barclays Capital, Inc.

Rogoff, K (1996): "The purchasing power parity puzzle", Journal of Economic Literature, vol 34, pp 647-68.

Stock, J and M Watson (1988): "Variable trends in economic time series", Journal of Economic Perspectives, vol 2, no 3, pp 147-74.

Upper, C and T Werner (2007): "The tail wags the dog: time-varying information shares in the Bund market", BIS Working Papers, no 224.

Wright, J (2008): "Term premiums and inflation uncertainty: empirical evidence from an international panel dataset", Finance and Economics Discussion Series paper, no 2008-25, Board of Governors of the Federal Reserve System. 